\title{
Nutrition and the training of doctors
}

\section{By June K. Lloyd, St George's Hospital Medical School, Cranmer Terrace, London $S W_{1} 7$ ORE}

The rapid growth in medical knowledge over the past few decades has resulted in overcrowding of the medical curriculum and subjects not perceived to be very useful in clinical medicine have tended to lose time to more promising or expanding topics (Anon., 1983). Because nutrition has been, until relatively recently, a neglected area of medical practice it has also been neglected in medical education. The British Nutrition Foundation, concerned that the resurgence of interest in nutrition and its importance in both the prevention and management of many diseases was not being incorporated into the training of doctors, set up a Task Force to survey the current status of courses in nutrition in undergraduate and postgraduate medical training; this paper summarizes the findings which have already been published in a report entitled Nutrition in Medical Education (British Nutrition Foundation, 1983).

\section{Nutrition in undergraduate medical education}

\section{Pre-clinical teaching}

A questionnaire on pre-clinical teaching was sent to the Heads of Departments of Biochemistry and/or Physiology in each of the thirty-one Medical Schools in the UK, of which twenty-nine responded. The replies revealed that only $41 \%$ had a specific individual to co-ordinate the teaching of nutrition in the pre-clinical course and $52 \%$ relied on departments outside the pre-clinical school to contribute to the teaching (in the majority of schools where this occurred a dietetic department was involved). In just over half the schools there were bridges between pre-clinical and clinical teaching.

In relation to the teaching of specific topics, the majority of schools taught about nutrient sources, requirements, deficiencies and excesses, and the role of nutrition in the aetiology and prevention of disease. However, the amount of time allocated varied widely from as little as $0.5 \mathrm{~h}$ on a topic, up to Io $\mathrm{h}$. There appeared to be little or no teaching in the areas of food toxicology and hygiene.

The over-all conclusion from analysis of the questionnaires was that in general the amount of time devoted to any nutritional topic in the pre-clinical years was very limited and that there appeared to be a lack of integration of nutritional teaching in the pre-clinical course as a whole.

\section{Clinical teaching}

The survey of clinical teaching was more limited, a questionnaire being sent by members of the Task Force to colleagues in their own specialities (child health, gastroenterology, obstetrics and gynaecology, and surgery). The over-all response 
rate was $89 \%$, and it was considered that this enabled a reasonable picture of the state of nutrition teaching in clinical courses to be obtained.

The replies indicated that there was very little co-ordination in the teaching of nutrition during undergraduate clinical training; indeed some respondents did not even think it desirable. In only half the schools were there specific teaching sessions on nutrition and very few schools could identify nutrition teaching occurring as a specific item during ward rounds. About one-quarter identified a need for additional time to be devoted specifically to nutritional topics. The contribution of departments outside the main clinical departments to nutrition teaching varied, but in just over half the schools dietetic staff were involved to some extent.

The general conclusion was that the amount of time allocated to nutrition in the clinical course was small and that there was little apparent planning or co-ordination of the teaching.

\section{Nutrition in postgraduate medical education}

Information proved difficult to obtain. It was sought from three sources: ( 1 ) the nutrition content of questions in higher examinations, (2) information on specific courses from postgraduate centres in eight randomly-selected regions in the UK, (3) information from three Community Medicine Consortia regarding their approach to nutrition education.

The nutritional component of higher examinations appeared to be small and only in the Faculty of Community Medicine did the syllabus for the Diploma of Membership emphasize nutrition.

Responses from postgraduate centres in eight regions in the UK was disappointing, only twenty-two replies being received out of 119 enquiries ( $18 \%$ ). Of those responding, few reported any regular courses relating to nutrition; $7 \%$ stated that at least one 'nutrition' lecture had been held during the preceding 5 years but in most cases the topic was enteral and parenteral feeding. Thus there did not seem to be great interest in nutrition as a subject for postgraduate education.

Replies from the Community Medicine Consortia indicated that the revised syllabus of the Faculty of Community Medicine was likely to result in more importance being placed on nutrition in health and disease in the training of community physicians.

\section{Recommendations}

The recommendations of the Task Force (British Nutrition Foundation, 1983) have also been summarized in the medical journals. In formulating these recommendations the futility of pleading for more space within an already over-full medical curriculum was fully recognized. The main points to be emphasized are the necessity of regarding the teaching of nutrition as a continuum starting in the pre-clinical years and proceeding throughout the clinical undergraduate and postgraduate stages of medical training. Within each Medical School there should 
be a co-ordinator for nutrition education and preferably this individual should be a member of an Academic Unit having a special interest in nutrition; this Unit could then act as a focal point for the organization of training. It would be the responsibility of the co-ordinator, assisted perhaps by a small standing committee, to ensure that properly-structured courses were incorporated into the basic science teaching in biochemistry and physiology and also within the clinical subjects.

For postgraduate education the postgraduate medical centres could initiate more on-going teaching by way of courses and lectures. In addition, the establishment of nutrition teams as part of the services of District General Hospitals should ensure that both the basic principles, and the clinical applications, of nutrition in relation to patient care are disseminated to the medical staff.

The Task Force did not wish to appear to be saying the last word on nutrition education; it considered that there could be a case for the educational bodies concerned with training to appoint a Working Party to review in more depth the present scope for education and nutrition of students and junior doctors and the need to strengthen academic departments to enable more research and teaching in nutrition to be carried out.

\section{REFERENCES}

Anon. (1983). Lancet $\mathbf{i}, \mathbf{1}_{422}$.

British Nutrition Foundation (1983). Nutrition in Medical Education, report of a Task Force on clinical nutrition. London: British Nutrition Foundation. 